\title{
Improving access to psychological therapies: a comparison between two devolved nations
}

\section{Louise Waddington* and Rebecca Jury}

Cardiff CBT Programmes, School of Psychology, Tower Building, Cardiff, UK

Received 19 December 2012; Accepted 12 May 2013

\begin{abstract}
Scotland and Wales share the opportunities of devolved government as well as challenges such as urban deprivation and remote rural communities. Such commonalities make a comparison of their approaches to psychological therapies relevant. The Scottish and Welsh governments have both published guidance concerning improved access to psychological therapies and these reveal different approaches. The Scottish Government has provided clear and concrete guidance for services, retains a close overview of progress, and plans training from the centre. The Welsh Government has published guidance which is unspecific, has largely devolved responsibility for implementation to local health boards and has no central plan for training. Scottish guidance provides clear information about who can expect to receive specific evidence-based therapies, the number of sessions they can expect to receive, and crucially the level of training and competence required for therapists. Welsh guidance documents have not yet specified which patient groups can expect to access formal psychological therapies, which psychological therapies are considered to have a sound evidence base, the number of sessions patients can expect, or the level of training and competence required for practitioners. Welsh policy documents make no reference to competence frameworks for therapists.
\end{abstract}

Key words: CBT, competence, IAPT, Scotland, training, Wales.

\section{Introduction}

A concern to improve access to psychological therapies has figured largely on the NHS agenda in Britain in recent years. In England this concern was driven by Lord Layard's report (2006) which highlighted the economic advantages of providing access to effective psychological therapies. This led to the Increasing Access to Psychological Therapies (IAPT) Programme. Scotland and Wales have not adopted England's IAPT programme but have developed independent models of increasing access to psychological therapies. Both nations have published relevant guidance (Scottish Government, 2011; Welsh Government, 2012). The shared opportunities and challenges of the two nations in terms of recently devolved

\footnotetext{
*Author for correspondence: Dr L. Waddington, Cardiff CBT Programmes, School of Psychology, Tower Building, 70 Park Place, Cardiff CF10 3AT, UK (email: louise.waddington@wales.nhs.uk).
} 
governments, and population issues such as urban deprivation and remote, rural communities make a comparison of their approaches to psychological therapies relevant.

This short review provides a brief overview of each country's approach to improving access to psychological therapies, incorporating the aims, strategy, policy implementation and performance management adopted in each. It then goes on to consider the specific factors of patients' expectations and training requirements in each country. A comparison of these factors is set out in Tables 1-7, covering the following:

\section{for patients' expectations}

- patient group,

- patient severity,

- expected level of therapy,

- expected treatment delivered.

for training requirements

- level of therapy,

- level of training/competences required.

Through the review it becomes apparent that many questions remain for improving access to psychological therapies in Wales and that there remains a need for national guidance for Wales setting out which therapies have the most robust evidence base, service models for delivering these, and training and supervision standards.

\section{Psychological therapies in Scotland}

\section{An overview of Scotland's approach to improving access to psychological therapies}

The Scottish Executive published a White Paper in 2006 entitled 'Delivering for Mental Health' (Scottish Executive, 2006) which set out a vision for promoting good mental health for everyone in Scotland. Crucial was commitment 4: 'We will increase the availability of evidence-based psychological therapies (PTs) for all age groups in a range of settings and through a range of providers.' This ambition was accompanied by a scoping exercise which identified that at the time psychological therapies in NHS Scotland tended to be ad hoc, lacking clarity on training standards, interventions delivered, expected waiting times and outcomes. Further drivers for change included an awareness of the disparity between access to physical and psychological services, and pressure from service users and carers.

The Scottish Government has provided clear targets for increasing access to psychological therapies. A notable example is the target to 'deliver faster access to mental health services by delivering 18 weeks referral to treatment for psychological therapies from December 2014'. The Scottish Government has also provided detailed guidance in the form of the Matrix (Scottish Government, 2011) which includes guidance on the most up-to-date evidence-based interventions, explains levels of supervision and training necessary for safe and effective psychological therapy, and provides information and advice on strategic planning.

A crucial element of the Scottish Government's strategy has been to assume central responsibility for access to psychological therapies, including the setting of performance targets, guidance on the delivery of effective services (the Matrix), support from the centre for re-design and centralized planning for training through NHS Education for Scotland (NES). 
NES is a clear example of central responsibility for access to services. It is a Scottish Special Health Board with a role of commissioning, quality assurance, and occasionally delivery of education across NHS Scotland. This facility for centralized planning for training in psychological therapies is believed to support equity of service provision across geographical areas and lead to economies of scale.

There is a strategy of holding an overview of progress towards targets and encouraging progress through regular performance review. For example, the target of 18 weeks from referral to treatment, was set at central government level, is monitored by local health boards who report back with monthly data submissions to central government, and is encouraged with regular newsletters setting out progress towards the target.

The strategy in Scotland has been to redesign current services and deliver training to the existing workforce rather than to introduce a new service as England has done with IAPT. The emphasis has been on evidence-based therapies with CBT as the main focus although NES and the Scottish Government have also supported training in a range of evidence-based interventions including interpersonal therapy, mindfulness and behavioural family therapy.

\section{Psychological therapies in Scotland: patients' expectations}

For different patient groups, the Matrix outlines the expected level of treatment and therapy as shown in Table 1.

The Matrix also outlines the expected types of treatment and intervention. It provides guidelines on what evidence-based interventions to use for every diagnostic classification. NES worked with specialists to collate the NICE and SIGN guidelines alongside seeking further input from expert opinion. The interventions are summarized in the Matrix with a recommendation level of $\mathrm{A}, \mathrm{B}$ or $\mathrm{C}$.

A: Highly recommended. At least one meta-analysis, systematic review, or randomized clinical trial (RCT) of high quality and consistency aimed at the target population.

B: Recommended. Well conducted clinical studies but no RCTs on the topic of recommendation directly applicable to the target population, and demonstrating overall consistency of results.

C: No evidence to date but opinion suggests that this therapy might be helpful. Widely held expert opinion but no available or directly applicable studies of good quality.

An example of the guidelines for generalized anxiety disorder is presented in Table 2.

At Scottish Government level the intervention focus has been on CBT because it is the therapeutic modality which currently has the widest evidence base and is most cited in the literature. However NES and the Scottish Government are supporting the development of stepped care approaches for a range of conditions and incorporating a range of therapeutic modalities, with the aim of incorporating further guidance as it becomes available.

\section{Psychological therapies in Scotland: training requirements}

The Matrix outlines: 
Table 1. The expected level of treatment and therapy for different patient groups as outlined by the Matrix (Scottish Government, 2012)

\begin{tabular}{|c|c|c|c|}
\hline $\begin{array}{l}\text { Patient group } \\
\text { Common mental health } \\
\text { problem: } \\
\text { stress/anxiety/depression }\end{array}$ & $\begin{array}{l}\text { Patient severity } \\
\text { Mild/moderate, with } \\
\text { little complexity and } \\
\text { limited effect on } \\
\text { functioning }\end{array}$ & $\begin{array}{l}\text { Expected level } \\
\text { of therapy } \\
\text { Low intensity }\end{array}$ & $\begin{array}{l}\text { Expected treatment } \\
\text { delivered } \\
\text { Supported self-help, } \\
\text { solution-focused problem } \\
\text { solving, structured anxiety } \\
\text { management groups, self- } \\
\text { help coaching }\end{array}$ \\
\hline $\begin{array}{l}\text { Common mental health } \\
\text { problems }\end{array}$ & $\begin{array}{l}\text { Moderate/severe with } \\
\text { significant } \\
\text { complexity and } \\
\text { effect on functioning }\end{array}$ & High intensity & $\begin{array}{l}\text { Standardized psychological } \\
\text { therapies - delivered to } \\
\text { protocol and normally } \\
\text { lasting between 6-16 } \\
\text { sessions }\end{array}$ \\
\hline $\begin{array}{l}\text { Moderate/severe mental } \\
\text { health problems with } \\
\text { significant effect on } \\
\text { functioning - specialist } \\
\text { areas, e.g. schizophrenia, } \\
\text { personality disorder, } \\
\text { bipolar disorder, eating } \\
\text { disorder, substance misuse }\end{array}$ & $\begin{array}{l}\text { Moderate/severe with } \\
\text { significant } \\
\text { complexity and } \\
\text { effect on functioning }\end{array}$ & $\begin{array}{l}\text { Specialist high } \\
\text { intensity }\end{array}$ & $\begin{array}{l}\text { Standardized psychological } \\
\text { therapies, developed and } \\
\text { modified for specific } \\
\text { patient groups. Normally } \\
\text { lasting 6-20 sessions }\end{array}$ \\
\hline $\begin{array}{l}\text { Complex enduring mental } \\
\text { health problems with a } \\
\text { high likelihood of } \\
\text { comorbidity and beyond } \\
\text { the scope on standardized } \\
\text { treatments }\end{array}$ & Highly complex & $\begin{array}{l}\text { Highly } \\
\text { specialist }\end{array}$ & $\begin{array}{l}\text { Highly specialist, } \\
\text { individually tailored } \\
\text { interventions, drawing } \\
\text { creatively on the } \\
\text { theoretical knowledge } \\
\text { base of the discipline of } \\
\text { psychology. Normally } \\
\text { lasting } \geqslant 16 \text { sessions }\end{array}$ \\
\hline
\end{tabular}

Table 2. Guidelines taken from the Matrix on the evidence-based interventions for generalized anxiety disorder

\begin{tabular}{|c|c|c|c|c|}
\hline \multicolumn{5}{|c|}{ Generalized anxiety disorder (GAD) } \\
\hline Level of severity & Level of service & $\begin{array}{l}\text { Intensity of } \\
\text { intervention }\end{array}$ & What intervention? & Recommendation \\
\hline \multirow[t]{3}{*}{ Mild } & \multirow[t]{3}{*}{ Primary care } & \multirow[t]{3}{*}{ Low } & Guided self-help & B \\
\hline & & & $\begin{array}{l}\text { Large group } \\
\text { psychoeducation }\end{array}$ & B \\
\hline & & & Brief counselling & $\mathrm{C}$ \\
\hline Moderate to severe & $\begin{array}{l}\text { Primary care/ } \\
\text { Secondary care }\end{array}$ & High & $\begin{array}{c}\text { CBT (8-16 sessions } \\
\text { over 3-6 months) }\end{array}$ & A \\
\hline Severe and chronic & Secondary care & High & $\begin{array}{l}\text { CBT (20 sessions } \\
\text { over } 6 \text { months) } \\
\text { delivered to a } \\
\text { specialist treatment } \\
\text { protocol for GAD }\end{array}$ & $\mathrm{C}$ \\
\hline
\end{tabular}


Table 3. Training and competences specified by the Matrix for delivering each level of therapy

\begin{tabular}{ll}
\hline Level of therapy & Level of training/competences required. \\
'Low intensity' treatment & Minimum training required; generally 5-10 days' training \\
& Intensive, ongoing supervision Level of competence must meet the \\
'Skills for Health' 'Low intensity' competences \\
'High intensity' therapy & Training required: diploma level At least 42 days of formal teaching, \\
& 24 days of CBT in the workplace \\
& Intensive supervision over at least 1 year of training \\
& Level of competence must meet the 'Skills for Health' 'High \\
intensity' competences & \\
Training required: diploma-level CBT training \\
'Specialist' therapy & Further training in application of CBT techniques to specialist area \\
& Further knowledge may be acquired through formal training or \\
& specialist supervision \\
& Level of competence must meet the 'Skills for Health' 'High \\
intensity' competences & Competences: specialist knowledge of a range of theoretical and \\
therapeutic models. Ability to formulate complex problems using a \\
range of psychological models, taking into account historical, \\
developmental, systemic and neuropsychological processes
\end{tabular}

(a) The basics required for delivering psychological therapy.

(b) The specific training and competences required to deliver different levels of therapy.

(c) The recognized evidence-based competence frameworks.

The Matrix states all mental health staff should have a basic level of psychological 'awareness' and 'literacy'; this should include:

- training in a basic psychological model to run in tandem with the medical model, and within which a basic psychological formulation of service user's problems can be constructed;

- training in listening and communication skills;

- training in basic counselling skills;

- training in self awareness and the role of the therapeutic relationship.

The Matrix specifies the level of training and competences required for delivering each level of therapy, referring to the UK Skills for Health (2011) (see Table 3).

The Matrix recognizes specific evidence-based competence frameworks provided by University College London (UCL, 1999-2013).

The delivery of psychological therapies is competence based and the Matrix specifies that staff involved in the delivery of care and of related teaching and training should be competent according to specific competence frameworks detailed on the UCL's website. UCL has provided evidence-based competency frameworks for the following approaches

- Cognitive and behavioural therapy for depression and anxiety (which differentiates between the competencies needed at the 'low intensity' and high intensity' levels within stepped care). 
- Psychoanalytic/psychodynamic competences.

- Systemic competences.

- Humanistic competences.

- Supervision competences.

Staff from any discipline who can demonstrate the relevant competences from the competency frameworks may be involved in delivery of care and of related teaching and training.

\section{Psychological therapies in Wales}

\section{An overview of Wales' approach to improving access to psychological therapies}

The Mental Health (Wales) Measure was approved in 2010 and seeks to improve accessing and receiving care and treatment in primary and secondary mental health services. Crucially, part 1 of the measure aims to 'expand the provision of local primary mental health support services'.

Like Scotland, the Welsh Government planned a scoping exercise across all local health boards to determine the current profile of psychological therapies in primary healthcare. This exercise was expected to be completed by summer 2011 but no details have yet been published. A further report by Health and Social Research has been commissioned to review access to and implementation of psychological therapy treatments in Wales. This report is still underway.

The Welsh Government has published two documents supporting the Mental Health Measure: The 'National Service Model for Local Primary Mental Health Support Services' (Welsh Government, 2011) offers guidance on implementing the Measure in primary care, and 'Psychological Therapies in Wales: Policy Implementation Guidance' (Welsh Government, 2012) discusses improved access and delivery of psychological therapies across the service. The more recent Policy Implementation Guidance (PIG) makes no reference to the earlier National Service Model and the information provided by the two documents is not integrated so that implementation of the guidance is somewhat open to local interpretation.

The Welsh Government, by contrast with the Scottish Government, has largely devolved responsibility for the implementation of policy to local health boards. There is therefore a risk of unequal access across geographical areas: first, unequal access to psychological therapy for clients, and second, unequal access to therapy training and supervision for practitioners. There is also considerable duplication of effort as each local health board plans how best to implement legislation. It is not clear that there is an overview at central government level of each local health board's progression towards implementing the Mental Health Measure.

\section{Psychological therapies in Wales: patients' expectations}

Information relevant to patients' expectations, from the National Service Model (Welsh Government, 2011) is given in Table 4. The more recent information in the Policy Information Guidance is given in Table 5 .

There are some details in the National Service Model that are not included in the more recent PIG. The former referred to local primary mental health support services including, 'a range of psychological interventions including cognitive behavioural therapy, 
Table 4. Information from the National Service Model (Welsh Government, 2011) relevant to patients' expectations

\begin{tabular}{|c|c|c|}
\hline Patient group/patient severity & $\begin{array}{l}\text { Expected level } \\
\text { of therapy }\end{array}$ & Expected treatment delivered \\
\hline Not specified & Foundation tier & $\begin{array}{l}\text { Self-help resources, mental health promotion and } \\
\text { education }\end{array}$ \\
\hline \multirow{7}{*}{$\begin{array}{l}\text { People of all ages who have } \\
\text { mild to moderate and/or } \\
\text { stable severe and enduring } \\
\text { mental health problems, } \\
\text { including psychosocial, } \\
\text { behavioural and emotional } \\
\text { difficulties experienced by } \\
\text { children and young people } \\
\text { and memory impairment } \\
\text { experienced by older people }\end{array}$} & Tier 1 & $\begin{array}{l}\text { The Primary healthcare team, local primary } \\
\text { mental health support services and related } \\
\text { services, Third sector services, Low support and } \\
\text { mainstream accommodation services, } \\
\text { Mainstream leisure, Education and recreational } \\
\text { services }\end{array}$ \\
\hline & & GP formal assessment, treatment \& management \\
\hline & & $\begin{array}{l}\text { Short-term interventions, either individually or } \\
\text { through group work, if the initial assessment has } \\
\text { identified this as appropriate. Such interventions } \\
\text { may include counselling, a range of } \\
\text { psychological interventions including CBT, } \\
\text { solution-focused therapy, family work, online } \\
\text { support, stress management, bibliotherapy and } \\
\text { education }\end{array}$ \\
\hline & & $\begin{array}{l}\text { Culturally appropriate, evidence-based } \\
\text { interventions which reflect individual need and } \\
\text { should receive a sufficient number of sessions to } \\
\text { give benefit. Such interventions are likely to be } \\
\text { appropriately delivered within 6-10 sessions in } \\
\text { most cases }\end{array}$ \\
\hline & & $\begin{array}{l}\text { Information and advice about interventions and } \\
\text { care, 'signposting' to other sources of support } \\
\text { and help in accessing services }\end{array}$ \\
\hline & Tier 2 & $\begin{array}{l}\text { Community mental health, including CRHT, } \\
\text { Assertive outreach, Early intervention functions, } \\
\text { Acute inpatient care, Supported accommodation } \\
\text { services, general services }\end{array}$ \\
\hline & Tier 3 & $\begin{array}{l}\text { Specialist inpatient services, e.g. low and medium } \\
\text { secure care specialist community teams }\end{array}$ \\
\hline Not specified & Tier 4 & $\begin{array}{l}\text { Highly specialist inpatient, high secure and } \\
\text { residential services }\end{array}$ \\
\hline
\end{tabular}

solution-focused therapy, family work, online support, stress management, bibliotherapy and education'. These specific therapies are not mentioned in PIG. However, PIG states that, 'services should offer a comprehensive range of formal high quality psychological therapies' and that, 'where relevant NICE guidance exists therapy should conform to the recommendations set out in these national guidelines'.

The most commonly cited therapy in NICE guidance is CBT. However, unlike Scotland's Guidance 'the Matrix', the PIG gives no clear guidance as to which patients can expect 
Table 5. Information from the Policy Information Guidance (Welsh Government, 2012) relevant to training

\begin{tabular}{|c|c|c|}
\hline Patient group/patient severity & $\begin{array}{l}\text { Expected level } \\
\text { of therapy }\end{array}$ & Expected treatment delivered \\
\hline Not specified & 0 & $\begin{array}{l}\text { Leaflets, local media, mental health first aid, } \\
\text { self-help resources - internet sites, } \\
\text { self-assessment, self-help literature, } \\
\text { computer-based CBT, stress control } \\
\text { courses, bibliotherapy (book prescription) }\end{array}$ \\
\hline Not specified & 1 & $\begin{array}{l}\text { As above and advice line, first-line } \\
\text { assessment appointments, signposting, } \\
\text { referral to appropriate step-up services }\end{array}$ \\
\hline Not specified & 2 & $\begin{array}{l}\text { A range of psychological interventions } \\
\text { including single model therapies and } \\
\text { integrative/multi-modal treatment } \\
\text { approaches }\end{array}$ \\
\hline Complex and enduring presentations & 3 & Specialist assessment and treatment \\
\hline Highly complex care & 4 & $\begin{array}{l}\text { Highly complex care (frequently continuing } \\
\text { care cases) }\end{array}$ \\
\hline
\end{tabular}

to receive CBT, how many sessions they may expect to receive or the qualifications of the practitioner.

The PIG offers no information as to which patients or what level of severity may be expected to access the different services.

\section{Psychological therapies in Wales: training requirements}

There is scant information available as to the training, qualifications and competencies required for psychological practitioners in Wales. The recent PIG acknowledges some difficulties with training:

Wales does not have a strategic programme to meet the training and development needs of staff working in Wales.

Information derived from the Wales National Service Model is given in Table 6.

The PIG describes three levels of mental health practitioner required to implement the Measure (for details see Table 7a).

The PIG does not explain which service level these practitioners are expected to work at and it does not relate them to the table provided as an example of tiered care. Information from this is provided in Table $7 b$.

Neither Welsh guidance document specifies the training or competences required for specific therapies. Accreditation with a 'nationally recognized accrediting body' is described but there is no matching of specific therapies to their relevant accrediting bodies. Skills for Health is not mentioned and neither are the UCL competency frameworks. 
Table 6. Information from the Wales National Service Model (Welsh Government, 2011) relevant to training

\begin{tabular}{ll}
\hline Level of therapy & Level of training/competences required \\
\hline Foundation tier & Mental health first aid within the community and across statutory, private and \\
Tier 1 & voluntary sectors for staff that have contact with the public. \\
& The practitioners who work within the local primary mental health support \\
& services will require several fundamental skills and competences to fulfil the \\
& functions set out in Part 1 of the Measure; i.e. to assess, provide interventions, \\
& refer, and provide advice and information to individuals, carers and primary \\
& care providers. \\
& It will be for local decision, dependent on the local configuration for the delivery \\
& of local primary mental health support services and local factors such as \\
& geography, demography and deprivation, and bearing in mind the importance \\
& of skill mix in determining outcome, as to how each service is staffed. An \\
& indicative ratio is one primary mental health worker for every 20000 population \\
& (all ages). \\
& It is expected that staff will have appropriate skills and experience for this work \\
& including language skills and will work within a recognized competency \\
& framework and within their limits of competency. It is also expected that staff \\
& will have regular professional supervision and regular opportunities for \\
& appropriate continued professional development. \\
& Not stated \\
Tier 2 & Not stated \\
Tier 3 & Not stated
\end{tabular}

Table 7a. Three levels of mental health practitioner described in the Policy Implementation Guidance (Welsh Government, 2012)

Level Level of training/competences required

A Mental health worker. Using engagement and the relationship, informed by counselling and psychotherapeutic skills, to promote change and recovery. Generic skills, requiring appropriate values and attitudes which can be taught and enhanced by reflective practice and supervision

B Practitioner able to deliver formulation-based or manualized evidence-based interventions for specific problems, through regular structured sessions for an agreed time. Requires training in the particular interventions appropriate to the particular diagnosed problems, and the theory underpinning them, and requires the practitioner to work under close consultative supervision

C Expert psychological therapist. Able to work with complex cases for whom level B interventions are not considered appropriate, or for whom they have failed to achieve the necessary outcomes. Able to work autonomously through formulation and using a particular model at high level, or through integration of different models or approaches. Able to apply models across different conditions and different contexts 
Table $7 \boldsymbol{b}$. An example of tiered care including training and competences described in the Policy Implementation Guidance (Welsh Government, 2012)

\begin{tabular}{lll}
\hline Level of therapy & Level of training/competences required \\
\hline $0 \quad$ Leaflets, local media, mental health & Mental health promotion network \\
first aid, self-help resources - internet & Third sector services \\
sites, self-assessment, self-help & Occupational health staff \\
literature, computer-based CBT, & Staff from higher tiers to perform particular tasks as \\
stress control courses, bibliotherapy & appropriate \\
(book prescription) & Psychological services staff, e.g. primary-care mental \\
$1 \quad$ As above and advice line, first-line & health workers, occupational health or HR staff with \\
assessments appointments, & IT and information management skills \\
signposting, referral to appropriate & Third sector services \\
step-up services & Professionally qualified staff to supervise/lead \\
& Professionally led staff, e.g. Wellbeing Through Work \\
& programme \\
& Professionally led psychological therapists trained to \\
& practitioner level or above \\
& First access teams \\
& GPs \\
& Clinical and counselling psychologists and \\
& psychotherapists Psychological therapists with \\
A range of psychological interventions & training equivalent to at least practitioner level \\
including single model therapies and & enabling accreditation and registration with a \\
integrative/multi-modal treatment & nationally recognized accrediting body \\
approaches & Clinical and counselling psychologists and \\
Specialist assessment and treatment & psychotherapists with training equivalent to at least \\
& practitioner level enabling regulation under HPC \\
& and/or registration with a professional body such as \\
Highly complex care (frequently & BACP/BABCP \\
continuing care cases) & Tertiary care \\
\hline & \\
\hline &
\end{tabular}

\section{Remaining questions for improving access to psychological therapies in Wales}

\section{Section 3.18 of the Wales National Service Model states:}

It is expected that the interventions will be recovery-focused, with clear expected outcomes, and will be underpinned and quality assured by evidence-based approaches. They will be based on a thorough assessment of each individual and delivered by suitably skilled and trained staff who are appropriately supervised.

but unlike Scotland's Matrix neither the National Service Model nor the PIG further operationalize the expected outcomes, the evidence-based approaches, the specific training and supervision of staff, and the skills required. This leads to the remaining questions for improving access to psychological therapies in Wales. 
Questions relating to patients' expectations:

(1) The Welsh National Service Model and PIG do not specify which patients can expect to be offered formal psychological therapy.

(2) The Wales National Service Model recommends 'interventions are likely to be appropriately delivered within 6-10 sessions in most cases' at tier 1 local primary mental health support services. How many therapy sessions at tiers 2, 3 and 4 can patients expect? The PIG offers no clarification.

(3) The Wales National Service Model states that patients can expect 'culturally-appropriate, evidence-based interventions'. What interventions does the service model consider evidence based? The PIG states that NICE guidance should be followed but does not integrate this guidance in its recommendations.

Questions relating to training required:

(1) Within the Matrix, the training required for each level of therapy is operationalized. For example, CBT practitioners are required to undertake 42 days of CBT teaching and 24 days of CBT practice. By comparison The Wales National Service Model and PIG fail to offer specific guidance as to the training required for any specific therapy.

(2) The National Service Model states 'It is expected that staff will work within a recognized competency framework and within their limits of competency' but no specific competency frameworks are recognized within the National Service Model or the PIG. By contrast the Scottish Matrix refers to the UK Skills for Health competencies and the competency frameworks provided by UCL.

(3) The most commonly cited therapy in NICE guidance is CBT but neither the National Service Model nor the PIG provide any guidance as to the training, qualifications, competencies or accreditation required to deliver CBT.

(4) The Welsh Government is currently funding a scheme which allows doctors to receive psychological therapy from private therapists. All therapists in this scheme are required to have $\mathrm{BABCP}$ accreditation as CBT practitioners. Why does guidance relating to therapy provision for the rest of the Welsh population not match this standard?

\section{Conclusions and recommendations}

(1) In order to provide the Welsh population with access to NICE-recommended psychological treatments there needs to be an increase in the capacity to deliver evidencebased therapies in Wales. In order to increase this capacity staff must be trained to practitioner level in therapies which have an evidence base for each disorder, and be provided with supervision which can maintain effective practice.

(2) Although no evidence is available as yet from Wales there is evidence from the early scoping exercise in Scotland that in the absence of clear training standards there can be no certainty that staff currently delivering therapy are adequately trained and supervised, or are delivering therapies appropriate to particular disorders. In the case of CBT there are risks to patients associated with CBT being practised by staff who have received inadequate training and supervision (Holland, 2006; BABCP, 2010), and one assumes this applies equally to other therapies. It would be helpful for the mapping exercises 
carried out on behalf of the Welsh Government to be published as soon as possible to get a clear view of current therapy provision and therapist training.

(3) The Scottish Matrix provides clear and concrete information for services with respect to psychological therapies. Wales has guidance that is less specific and leaves many questions unanswered. A further guidance document, integrating and superseding both the National Service Model for Local Primary Mental Health Support Services (2011) and the Psychological Therapies in Wales: Policy Implementation Guidance (2012) is needed. This could set out in a clear and concrete manner which therapies are considered to have the most robust evidence base, service models for delivering these, and training and supervision standards.

(4) Useful resources in drawing up clear recommendations include the competency frameworks produced in partnership between UCL, IAPT and NES, Skills for Health, the Scottish Matrix (2011) document, and crucially, consultation with service users and carers, e.g. groups such as OCD-UK.

(5) Once clear guidance is available it should be produced in a suitable format for service users and carers, setting out the services they can expect to receive: who can expect to receive psychological therapy; which interventions are considered to have a sound evidence base; the qualifications, training and supervision required for therapists, and the number of sessions they can expect to receive.

(6) Clear guidance could help prevent geographical inequalities in access to psychological therapy for patients and access to training for practitioners.

\section{Acknowledgements}

We are grateful to all who responded to the consultation document which preceded this publication.

\section{Declaration of Interest}

None.

\section{References}

BABCP (2010). Standards of Conduct, Performance and Ethics (http://www.babcp.com/files/ About/BABCP-Standards-of-Conduct-Performance-and-Ethics.pdf). British Association of Behavioural and Cognitive Psychotherapy. Accessed 18 December 2012.

Holland R (2006). Expanding cognitive therapy. BABCP Magazine (Training Supplement), February. BABCP, Accrington.

Layard R, Clark D, Bell S, Knapp M, Meacher B, Priebe S, Turnberg L, Thornicroft G, Wright B (2006). The Depression Report: a new deal for depression and anxiety disorders. The Centre for Economic Performance's Mental Health Policy Group, LSE.

Scottish Executive (2006). Delivering for Mental Health (http://www.scotland.gov.uk/Resource/Doc/ 157157/0042281.pdf). Accessed 18 December 2012.

Scottish Government (2011). The Matrix: Mental Health in Scotland: a guide to delivering evidence based psychological therapies in Scotland (http://www.skillsforhealth.org.uk/). Accessed 18 December 2012.

Skills for Health (2011). (http://www.skillsforhealth.org.uk/). Accessed 24 May 2013. 
UCL (1999-2013). University College London Centre for Outcome Research and Effectiveness (CORE) Competence frameworks for psychological therapies (http://www.ucl.ac.uk/clinical-psychology/ CORE/competence_frameworks.htm). Accessed 24 May 2013.

Welsh Government (2011). Mental Health (Wales): Measure 2010 National Service Model for Local Primary Mental Health Support Services (http://wales.gov.uk/docs/dhss/publications/ 110914mhnatservicemodelen.pdf). Accessed 18 December 2012.

Welsh Government (2012). Psychological Therapies in Wales. Policy Implementation Guidance (http://wales.gov.uk/docs/dhss/publications/120326psychologicalen.pdf). Accessed 18 December 2012.

\section{Learning objectives}

(1) Gain an understanding of the different approaches to increasing access to psychological therapies taken in Scotland and Wales.

(2) Learn what information is provided by the Scottish Matrix document about patients' expectations and training requirements for the provision of psychological therapy.

(3) Learn what information is provided by the Welsh policy documents about patients' expectations and training requirements for the provision of psychological therapy.

(4) Consider the remaining questions for services in Wales. 